\title{
Preliminary Study on Counterfeiting of Artemether and Artesunate Marketed in Lubumbashi
}

\author{
Pierrot Mwamba Tshilumba ${ }^{1,2}$, Elie Rongorongo Kagoha1, Valentin Bashige Chiribagula ${ }^{2,3}$, \\ Glauber Mbayo Kalubandika ${ }^{3}$, Vianney Ntabaza Ndage ${ }^{3}$, Trésor Sumbu Nzuzi ${ }^{3}$, \\ Evodie Numbi Wa Ilunga ${ }^{3}$, Pierre Duez ${ }^{2}$, Jean Baptiste Kalonji Ndoumba ${ }^{1}$ \\ ${ }^{1}$ Laboratory of Galenic Pharmacy and Drug Analysis, University of Lubumbashi, Lubumbashi, Democratic \\ Republic of Congo \\ ${ }^{2}$ Laboratory of Therapeutic Chemistry and Pharmacognosy, University of Mons, Mons, Belgium \\ ${ }^{3}$ Laboratory of Pharmacognosy, University of Lubumbashi, Lubumbashi, Democratic Republic of Congo \\ Email: pierrotmwamba@gmail.com
}

Received 28 March 2016; accepted 20 May 2016; published 23 May 2016

Copyright (C) 2016 by authors and Scientific Research Publishing Inc.

This work is licensed under the Creative Commons Attribution International License (CC BY). http://creativecommons.org/licenses/by/4.0/

(c) (i) Open Access

\begin{abstract}
Pharmaceutical counterfeiting is a health scourge responsible for several cases of morbidity and mortality. Counterfeit medicines cause therapeutic failure, emergence of resistance in the treatment of infections. This study was conducted in order to identify counterfeit and authentic medicines in circulation in Lubumbashi. The study included artemether and artesunate for oral administration. A careful visual inspection of medicine, investigation of authenticity of pharmaceutical products from manufacturers and pharmaceutical regulatory authorities and determination of content were used as study parameters. 52 samples: 37 artemether and 15 of artésunate were collected. 7 samples (13\%) have proven to be counterfeit. Artemether was the most counterfeit (71\%) and $29 \%$ for artesunate. $6(12 \%)$ samples were substandard according to the international pharmacopoeia in terms of content of active ingredient. Sixty-seven percent of non-compliance concerned counterfeit medicines. The proportion of non-compliance is highest among counterfeit medicines $(71.43 \%$ vs $2.22 \%$; $p=0.000004)$. It is obvious that strengthening the capacity of the drug regulatory authority of the DRC reduces the influx of counterfeit drug and substandard.
\end{abstract}

\section{Keywords}

Counterfeit, Medicines, Antimalarial, Lubumbashi, DR Congo 


\section{Introduction}

The drug counterfeiting represents a health scourge responsible for several cases of morbidity and mortality [1] [2]. The use of counterfeit drugs can increase the risk of therapeutic failure in the treatment of various diseases and it can also be the basis of drug intoxications [3] [4]. It is estimated that over $10 \%$ of drugs in circulation in the world are counterfeit but the rate is much higher in developing countries because of the weakness and lack of drug regulatory systems [5] [6].

Counterfeiting affects all types of medicine, however, the medicines concerned are not the same across countries. In industrialized countries, the targets tend to be lifestyle medicines such as narcotics or treatments for erectile dysfunction. Poor countries are mainly affected by counterfeit antiparasitics [1] [7].

Counterfeiting antimalarial drugs in developing countries such as DR Congo are increasingly seen as a major threat to public health. Artemether and artesunate are among the most widely used antimalarial, they are used in combination therapeutic such as Artemisinin-based combination and are recommended as first-line drug in the treatment of malaria [8]-[10].

Artemether and artesunate (Figure 1 and Figure 2) are metabolized by the CYP enzymes including CYP2B6 and CYP3A4 to active dihydroartemisinin (DHA), which is further metabolized (via glucuronidation and/or oxidation) to inactive products, they produce more profound reductions in parasitaemia and more rapid symptom relief than agents from any other anti-malarial class [11] [12]. The growing need for their use in the treatment of malaria makes them the most targeted by counterfeiters.

Considering all questions above-mentioned, it seemed important to conduct a study on counterfeiting of artemether and artesunate with the objective to identify counterfeit and genuine medicines marketed in Lubumbashi and assess the quality of all samples concerned by this study.

\section{Material and Methods}

Geographically this study included drugs obtained in Lubumbashi, provincial capital of Haut-Katanga, southeastern province of Democratic Republic of Congo, the city has seven townships: Lubumbashi, Kampemba,

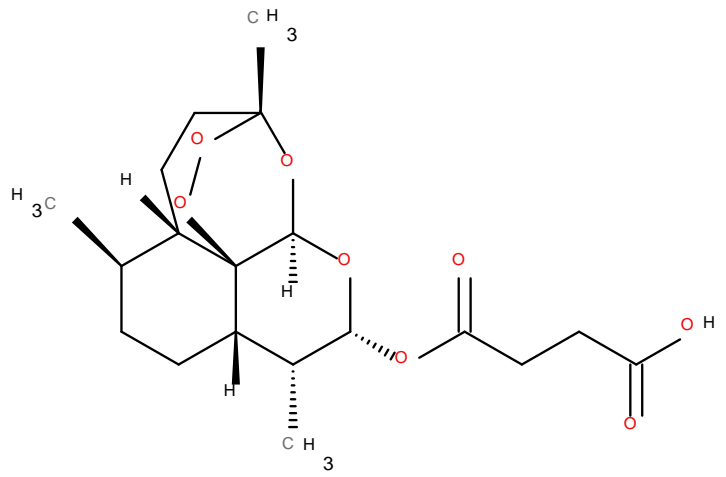

Figure 1. Chemical structure of artesunate.

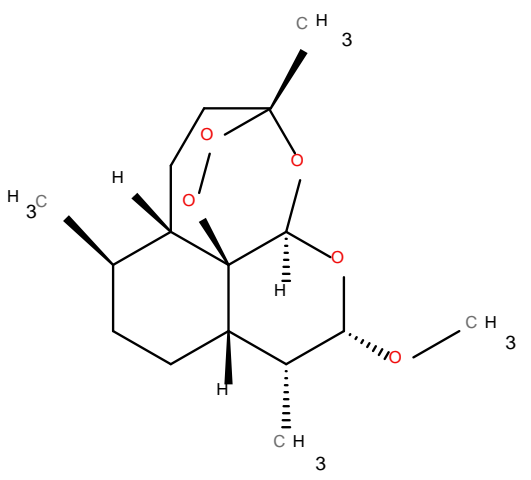

Figure 2. Chemical structure of artemether. 
Kamalondo, Kenya, Katuba, Ruashi and Annex. The samples were collected in four types of pharmaceutical establishment: establishment of wholesale, pharmacies opened to public, hospital pharmacies and public market.

\subsection{Sampling Method}

Samples were purchased from $15^{\text {th }}$ December 2014 to $10^{\text {th }}$ January 2015. The selection of collecting site were not the same for the types of pharmaceutical structures indicated above, thus, establishment of wholesale are twenty-two in Lubumbashi, they are all located in Lubumbashi city center and have been all selected as the collecting site of our samples. Regarding hospital pharmacies, general reference hospitals are eleven (Katuba, Kamalondo, Kenya, Kisanga, Kampemba, Jason Sendwe, Ruashi, Vangu, Munua, Tshiamilemba and Kowe), they were automatically chosen for the collection site of our samples. Concerning pharmacies opened to public, their selection was made randomly, we randomly selected 5 pharmacies in each township of the city of Lubumbashi. Public market where medicine are sold are six in Lubumbashi Kenya, Zambia, M'zee, Texaco, Congo and Katuba, we selected all those markets to collect our samples.

Each sample was collected with his withdrawal slip which contains the necessary informations on the traceability of samples collected: active ingredient and strength, brand name, manufacturing and expiring date, batch number, registration number, quantity purchased, date and place of collection and the price of each samples acquired.

Samples which were collected from the same or different pharmaceutical establishment and carrying a label indicating the same mentions: active ingredient, brand name, name and address of the manufacturer or marketer, the number of marketing authorization, batch number, date of manufacture and expiry, batch number, and having the same pharmaceutical form and strength were considered as one sample.

For the purpose of authenticity investigation, the medicines were required to be sold with their outer containers (boxes or plastic bags), or at least with their blisters, providing minimum information about the manufacturer or marketer and the batch/lot number.

Pharmaceutical forms that were involved in this study are those for oral administration, i.e. tablets, capsules, and oral suspensions. All the samples were kept at room temperature until analysis.

The standards used have been ordered and obtained from approved by Sigma Aldrich. In Table 1, we give information on standard products used.

\subsection{Observational Analysis}

Identification of a potentially counterfeit medicine passes first through careful visual inspection of the product. It consisted in examining: the location of mentions on the packaging, the physical aspect of pharmaceutical forms, the bar code, hologram, logo, typography, drawings or pictures, spelling words, language(s) mentioned (s) by the manufacturer, the instructions, the color of the packaging and product etc. [13] [14].

Each sample received a visual inspection questionnaire which incorporated informations on the samples collected including: primary and secondary packaging, physical appearance of tablet, capsule, solution for oral drop and powder for suspension, the particle size powders for drinkable suspensions forms...

\subsection{Investigation of Authenticity}

Besides complete analytical tests, WHO advises to contact the manufacturer on the label and the pharmaceutical regulatory authorities (PRA) of the country of marketing and manufacturing [14] [15]. In this study, we went to meet the pharmaceutical regulatory authority of DR Congo. The purpose of this investigation was to verify whether medicines collected in the pharmaceutical market were legally marketed in Lubumbashi. Thus, a formulary was intended for the local pharmaceutical regulatory authority who has the official list of medicines registered and authorized to be marketed in DR Congo. Concerning authenticity from manufacturers, they were contacted by using labels, online searches, e-mail and telephone communication. Portions of all samples were sent to the manufacturer with a request for authentication.

\begin{tabular}{|c|c|c|c|c|}
\hline $\mathrm{N}^{\circ}$ & Product & Batch $n^{\circ}$ & Supplier & Reference \\
\hline 1. & Artesunate & 099K1322 & Sigma-Aldrich & A3731 \\
\hline 2. & Artemether & $1,042,780$ & Sigma-Aldrich & $1,042,780$ \\
\hline
\end{tabular}




\subsubsection{Chemical Analysis}

The molecules concerned by this study were identified by thin layer chromatography and color reactions. The assay was performed by titrimetry and UV visible Spectrophotometry [16].

\subsubsection{Artésunate}

TLC: Dissolve $0.10 \mathrm{~g}$ of artesunate sample in acetone and make up to $10 \mathrm{ml}$ with the same solvent. Reference solution: Dissolve $0.10 \mathrm{~g}$ of artesunate in acetone and make up to $10 \mathrm{ml}$ with the same solvent; Drop in spot on the aluminum plate $5 \mathrm{ml}$ of each solution; Develop over a path of $15 \mathrm{~cm}$ using a mixture of petroleum ether and ethyl acetate $(7 \div 3)$; Dry the plate in ambient air; Detecting the spots by spraying the vanillin sulfuric acid solution. Results: If the sample contains artesunate, the task of the chromatogram obtained with the test solution has the same Rf value as that of the task of the control product. The Rf is the rapport between the distance traveled by the compound and the distance traveled by the solvent front.

Colour Reaction: A quantity of powder equivalent to $0.1 \mathrm{~g}$ of artesunate, add $40 \mathrm{ml}$ of absolute alcohol, shake and filter; Add $0.5 \mathrm{ml}$ hydroxylamine chloride in the half of the filtrate and $0.25 \mathrm{ml}$ of sodium hydroxide (80 g/l); Heat the mixture in a boiling water bath; Allow to cool, add 2 drops of hydrochloric acid (70 g/l) and 2 drops of ferric chloride (50 g/l), a light purple color is obtained; Evaporate the rest of the test filtrate "A" until a volume of about $5 \mathrm{ml}$; Put a few drops in a bowl in white porcelain; Add a drop of vanillin/sulfuric acid and let stand 30 minutes: a red coloration occurs when the presence of artésunate.

Determination of Content: A quantity of powder equivalent to $0.5 \mathrm{~g}$ of artesunate, add $50 \mathrm{ml}$ of neutralized ethanol, stir (1000 rpm about 15 minutes), filter by abandoning the first milliliters of the filtrate; Measure $25 \mathrm{ml}$ of the filtrate with sodium hydroxide $(0.05 \mathrm{~mol} / \mathrm{l})$; Use 2 drops of phenolphthalein indicator. Each $\mathrm{ml}$ of sodium hydroxide is equivalent to $19.22 \mathrm{mg}$ artésunate.

\subsubsection{Arteméther}

TLC: Dissolve $0.10 \mathrm{~g}$ of artemether sample in toluene and complete to $10 \mathrm{ml}$ with the same solvent. Reference solution: Dissolve $0.10 \mathrm{~g}$ of artemether in toluene and complete to $10 \mathrm{ml}$ with the same solvent. Place on the alumina plate $2 \mathrm{ml}$ of each solution; Develop over a path of $15 \mathrm{~cm}$ with a solvent system consisting of toluene and ethyl acetate $(95 \div 5$ ); The plate is dried in ambient air and spraying anisaldehyde/methanol, heating the oven at $120^{\circ} \mathrm{C}$ for 5 minutes; Examine under ultraviolet light at $254 \mathrm{~nm}$. Results: If the sample is artemether, the task of the chromatogram obtained with the test solution is similar in height to the task of the control product.

Colour Reaction: A quantity of powder corresponding to $0.08 \mathrm{~g}$ of artemether, add $40 \mathrm{ml}$ of absolute alcohol, shake and filter; Evaporate half of the filtrate to about $1 \mathrm{ml}$, add $0.10 \mathrm{~g}$ of potassium iodide and heated, a yellow color is obtained; Evaporate the other half of the test filtrate "A" in a volume of about $5 \mathrm{ml}$; Put a few drops in a bowl in white porcelain; Add a drop of vanillin/sulfuric acid, a pink color is obtained.

Determination of Content: Weigh a quantity of powder corresponding to $13 \mathrm{mg}$ of Artemether accurately weighed, put the powder into a $100 \mathrm{ml}$ volumetric flask and bring to volume with absolute ethanol; Shake well for about 15 minutes and filter, discard the first $10 \mathrm{ml}$ of the filtrate; Measure exactly $5 \mathrm{ml}$ of the clear filtrate, put in a $50 \mathrm{ml}$ flask and dilute up to the mark with $\mathrm{HCl}$ ethanolic $1 \mathrm{~mol} / \mathrm{l}$; Stir and heat in a water bath at a temperature of $55^{\circ} \mathrm{C}$ for 5 hours; cool to room temperature; Operate the spectrophotometric analysis using absolute alcohol hydrochloride solution $(1 \mathrm{~mol} / \mathrm{l})$ as white; Determine the absorbance at the wavelength of $254 \pm 1 \mathrm{~nm}$ and calculate the artemether content using the following formula.

$$
\text { Percentage content }(\%)=\frac{\text { absorbance of sample } \times 100}{\text { absorbance of standard }} \text {. }
$$

\subsubsection{Statistical Analysis}

Data analysis was performed using Epi-info version 7.0. The p value was determined to check whether the results were statistically significant.

\section{Results and Discussion}

\subsection{Sampling}

52 samples were collected: 37 of artemether and 15 of artesunate. Establishments of wholesale provided 19 (37\%) samples, followed by pharmacies opened to public pharmacies 15 (27\%), and respectively $21 \%$ and $13 \%$ for 
public market and hospital pharmacies. The predominance of samples provided by establishments of wholesale is explained by the fact that they supply the majority of other pharmaceutical establishments: pharmacies opened to public, hospital pharmacies and the drugs sold in public markets. The most represented pharmaceutical form is tablet with 39 (75\%) samples followed by oral suspension 13 (25\%). 38\% of samples collected are manufactured in India (Figure 3), Chine represent 17\% of samples collected followed by DR Congo (13\%), Italia (12\%) and $10 \%$ for Belgium and Switzerland.

\subsection{Authenticity}

Investigation of samples authenticity from pharmaceutical regulatory authorities (PRA) of the country of marketing revealed that 12 (33\%) samples were not authorized and not registered to be marketed in Democratic Republic of Congo. 10 (83\%) cases concerned artemether, and 2 (17\%) concerned artesunate. Samples illegally marketed in DR Congo are mostly from Asia 69\%, 48\% for India and 21\% for China, the samples produced locally represent $31 \%$ as shown in Figure 4.

Requests were sent asking 13 manufacturers to authenticate 38 products. 3 manufacturers could not be contacted. Six manufacturers responded for 18 (47\%) of the samples. 7 samples were described counterfeit and 30 as authentic.

We give in Figure 1 the illustration of counterfeiting detected. Indeed, the counterfeit medicine represented in Figure 5, reproduce exactly the genuine package but we can observe that the picture which is on the counterfeit sample is more deeper red than picture which is on genuine package. We can also observe that the validity date of counterfeit sample is for 4 years but it's for 2 years on the genuine package. After inquiries from the genuine manufacturer, date of manufacture and expiry, batch number have been incorrect.

The investigation method of drugs authenticity has been practiced rarely and often incomplete, because of the time and budget required for its efficient working. This is the case of Khail et al. (2013) [15] who investigated the authenticity of drugs from medical regulatory authority of manufacturers country and manufacturer, only 3 of 11 medical regulatory authority replied to requests for verification of the legitimacy of manufacturers and samples. Six of 15 manufacturers participated to the study.

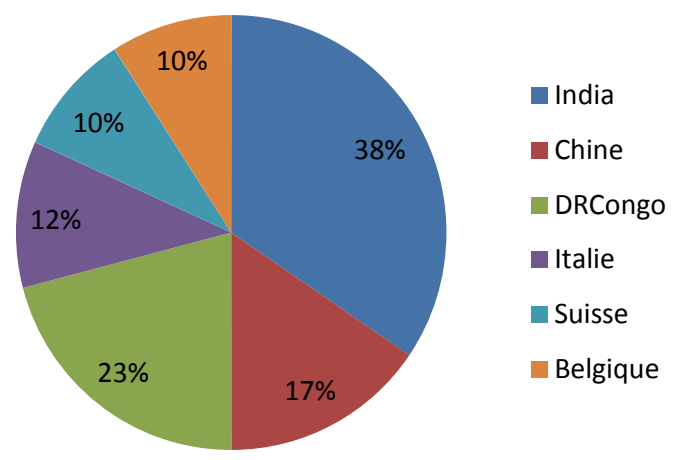

Figure 3. Distribution of samples collected according to origin country.

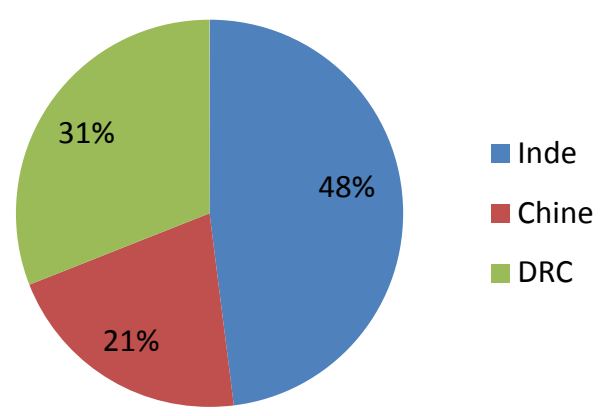

Figure 4. Distribution of samples illegally marketed in the DRC according to origin country. 


\subsection{Identification}

All samples contained the active ingredients (artemether and artesunate). Our results differ from those obtained by Nnanga et al. (2015) [17] who found that out of 30 samples, $10 \%$ of them did not contain Artemether, the samples were from Yaounde illicit market. Tipke et al. (2008) [18] obtained 100\% positive responses by identifying Artesunate with colorful reactions and TLC examining nine and fifteen samples respectively. The same percentage was obtained by Bate et al. in 2008 [19] working on 32 formulations.

\subsection{Content Analysis}

Of 52 samples, 6 (12\%) were non-complaints according to the International Pharmacopoeia in terms of content of active ingredient (90\% - 110\%) including 4 (67\%) of artesunate and 2 (33\%) of artemether. The active ingredient was lower amount (under-dosing) for all samples non complaints. Artesunate is the most represented with 4 samples (67\%) non-compliants, followed by artemether with 33\%. 4 cases of non compliance concerned the tablet form and 2 for oral suspension. Non-compliant samples found were from market public (83\%) and pharmacy opened to public (17\%). All 4 products dosed by Dondorp et al. (2004) [20] in Southeast Asian meet the standards of the International Pharmacopoeia. Elsewhere, non-compliance of samples concerned three countries: Italia (2 samples), DRC (2 samples) and India (2 samples).

Out of 6 Samples non complaints (Table 2), counterfeit samples detected in this study represent $71 \%$ (5 samples) of non-compliance. All of them were the case of under-dosing.

It has been reported that counterfeit drugs are rarely effective and even dangerous and harmful to human health [3] [12]. Aka et al. (2005) [14] found that from 44 samples collected in Cote d'Ivoire, 42 were not registered, the determination of content active ingredient revealed that only one sample were not compliant (absence of active ingredient), this sample were not registered in Côte d'Ivoire and were declared to be counterfeit.

All counterfeit drugs were from public market. This finding corroborates the advanced data by several studies: the significant presence of the illegal market is a potential factor favouring the circulation of counterfeit drugs. All counterfeit samples had an identifiable country of origin: 60\% were from India and 40\% from Italia. Delepierre et al. (2012) [8] found that 78\% of counterfeit anti-infectives detected in their study were from Asia.

From the above, comparing non complaints between counterfeit and authentic samples, we find in this study that the proportion (Table 3 ) of non-compliance is the highest among the counterfeit samples $(71.43 \%$ vs $2.22 \%$; $\mathrm{p}=0.000004)$.

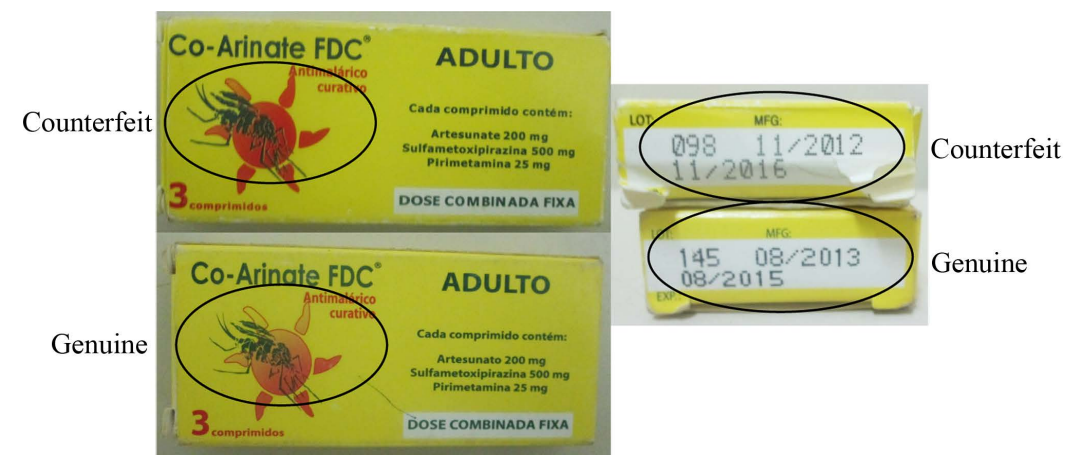

Figure 5. Illustration of counterfeiting detected.

Table 2. Results of non-compliance of counterfeit samples.

\begin{tabular}{cccccc}
\hline $\mathrm{N}^{\circ}$ & Sample & Active ingredient & Galenic form and strength & Content obtained (\%) & Conclusion \\
\hline 1. & Art 8 & Artemether & Suspension $80 \mathrm{mg}$ & 73 & Non-complaint \\
2. & Art 19 & Artemether & Suspension $80 \mathrm{mg}$ & 62 & Non-complaint \\
3. & Asu 32 & Artesunate & Tablet $200 \mathrm{mg}$ & 52 & Non-complaint \\
4. & Asu 47 & Artesunate & Tablet $200 \mathrm{mg}$ & 49 & Non-complaint \\
5. & Art 25 & Artemether & Tablet $80 \mathrm{mg}$ & 42 & Non-complaint \\
\hline
\end{tabular}

Legend: Art = artemether; Asu = artesunate. 
Table 3. Conformity of active ingredient content of samples according to their authenticity.

\begin{tabular}{cccc}
\hline & Medicines complaints & Medicines non complaints & Total \\
\hline Counterfeit sample & 2 & 5 & 7 \\
Authentic sample & 44 & 1 & 45 \\
\hline
\end{tabular}

\subsection{Study Limits}

Though the purchase of sample were done with discretion so as not to attract the attention of people around, in public markets, the sale of drugs is an activity that is not officially recognized by the authorities, some sellers mobile or fixed have been reluctant to us, that situation it did not allow us to gain some desired samples. It is true that the sample size can not be generalized to overall pharmaceutical market in Lubumbashi but it reflects the situation of the pharmaceutical market in Lubumbashi and for the first time this study gave interesting information on counterfeit and genuine medicines marketed in Lubumbashi.

\section{Conclusions}

This study was undertaken with the aim of detecting counterfeit and authentic drugs marketed in Lubumbashi and to assess the quality of all medicines collected.

The study showed that Lubumbashi was not saved by counterfeiting phenomenon and drug counterfeit represented a potential risk in the treatment of malaria because $71 \%$ of non-compliance found in this study concerned counterfeit medicines.

It is obvious that strengthening the capacity of the pharmaceutical regulatory authority of DRC will reduce the presence of counterfeit/substandard drugs. It is also essential that a strengthened control at the borders must be permanent in order to reduce the presence of substandard/counterfeit drugs in the pharmaceutical market of Congo.

In the future, a deep study will allow: 1) to determine the prevalence of counterfeit active ingredients concerned by this study in Lubumbashi 2) to widen the sample size 3) to add other laboratories tests (galenic tests and determining content active by HPLC) to assess the impact of the active ingredients on human health.

\section{Acknowledgements}

We thank the ARES-CCD (Academie de Recherche et de l'Enseignement Superieur-Commission de la Coopération au Developpement) for the sustain that we benefited to realize this study. We are also grateful to pharmaceutical regulatory authority of Lubumbashi, particularly Inspector Pharmacist for its collaboration.

\section{Conflict of Interest Statement}

The authors declare no conflict of interest.

\section{References}

[1] Dégardin, D., Roggo, Y. and Margot, P. (2014) Understanding and Fighting the Medicine Counterfeit Market. Journal of Pharmaceutical and Biomedical Analysis, 87, 167-175. http://dx.doi.org/10.1016/j.jpba.2013.01.009

[2] Blackstone, E.A., Fuhr, J.P. and Pociask, S.M.A. (2014) The Health and Economic Effect of Counterfeit Drugs. American Health and Drug Benefits, 7, 216-224.

[3] Newton, P.N., Tabernero, P. and Dwivedi, P. (2014) Falsified Medicines in Africa: All Talk no Action. Lancet Global Health, 2, e509-e510. http://dx.doi.org/10.1016/S2214-109X(14)70279-7

[4] Kelesidis, T. and Falagas, M.E. (2015) Substandard/Counterfeit Antimicrobial Drugs. Clinical Microbiology Reviews, 28, 443-464. http://dx.doi.org/10.1128/cmr.00072-14

[5] Fernandez, F.M., Green, M.D. and Newton, P.N. (2008) Prevalence and Detection of Counterfeit Pharmaceuticals: A Mini Review. Industrial and Engineering Chemical, 47, 585-590. http://dx.doi.org/10.1021/ie0703787

[6] Mackey, T.K. and Liang, B.A. (2011) The Global Counterfeit Drug Trade: Patient Safety and Public Health Risks. Journal of Pharmaceutical Sciences, 11, 4571-4579. http://dx.doi.org/10.1002/jps.22679

[7] Delepierre, A., Gayot, A. and Carpentier, A. (2012) Update on Counterfeiting Antibiotic Worldwide: Public Health 
Risks. Médecine et Maladies Infectieuses, 42, 247-255. http://dx.doi.org/10.1016/j.medmal.2012.04.007

[8] Newton, P., Proux, S., Green, M., Smithuis, F., Rzendaal, J., Prakongpan, S., et al. (2001) Fake Artesunate in Southeast Asia. The Lancet, 357, 1948-1950. http://dx.doi.org/10.1016/S0140-6736(00)05085-6

[9] Kelesidis, T., Kelesidis, I., Rafailidis, I.P. and Falagas, M.E. (2007) Counterfeit or Substandard Antimicrobial Drugs: A Review of the Scientific Evidence. Journal of Antimicrobial Chemotherapy, 60, 214-216. http://dx.doi.org/10.1093/jac/dkm109

[10] Mbinze, M.J., Nsangu, M.J., Maghe, E., Kobo, S. and Mwanda, R. (2015) Application of Total Error Strategy in Validation of Affordable and Accessible UV-Visible Spectrophotometric Methods for Quality Control of Poor Medicines. American Journal of Analytical Chemistry, 6, 106-117. http://dx.doi.org/10.4236/ajac.2015.62010

[11] Liusheng, H., Sunil, P., Rosenthal, P.J., Patricia, L., Marzan, F. and Dorsey, G. (2012) Concomitant Efavirenz Reduces Pharmacokinetic Exposure to the Antimalarial Drug Artemether-Lumefanthrine in Healthy Volunteers. Journal of Acquired Immune Deficiency Syndromes, 61, 310-316.

[12] Morris, A.C., Duparc, S., Borghini-Fuhrer, I., Jung, D., Shin, C.-S. and Fleckenstein, L. (2011) Review of the Clinical Pharmacokinetic of Artésunate and Its Active Metabolite Dihydroartemisinin Following Intravenous, Intramuscular, Oral or Rectal Administration. Malaria Journal, 10, 263. http://dx.doi.org/10.1186/1475-2875-10-263

[13] WHO. Counterfeit Drugs, Guidelines for the Development of Measure to Combat Counterfeit Drugs. Department of Essential Drugs and Other Medicines. Geneva, Switzerland. http://apps.who.int/iris/bitstream/10665/65892/1/WHO_EDM_QSM_99.1.pdf

[14] Aka, E., Legris, C., Tanimoto, T., Matsushita, R. and Kimura, K. (2005) Counterfeit Medicine Detection by Authenticity Investigation: A Pilot Study in the Street Market of Côte d'Ivoire. Japanese Society of Social Pharmacy, 24, 7-16.

[15] Khail, M.H., Hatanaka, K., Sovanarith, T., Nivanna, N., Cadena, L.C. and Yoshida, N. (2013) Effects of Packaging and Storage Conditions on the Quality of Amoxicillin-Clavulanic Acide-An Analysis of Cambodian Samples. Pharmacology and Toxicology, 14, 33-45.

[16] WHO. International Pharmacopeia. Tests and General Requirements for Dosage Forms Pharmaceutical Substances and Tablets. Vol.5, 3rd Edition, Geneva.

[17] Nnanga, N., Eboumbou, M., Ngene, J.P., Ewoudou, M.E.R. and Mpondo, M.E. (2015) Pharmaco-Technical Evaluation of Antimalarial Drugs from Licit and Illicit Market in Yaounde Case Of Artemether-Lumefanthrine 20/120. Health Sci. Dis, 16, 1-5.

[18] Tipke, M., Diallo, S., Coulibaly, B., Störzinger, D., Hoppe-tichy, T., Sie, A. and Müller, O. (2008) Substandard Anti-Malarial Drugs in Burkina Faso. Malaria Journal, 7, 95.

[19] Bate, R., Coticelli, P., Tren, R. and Attaran, A. (2008) Antimalarial Drug Quality in the Most Severely Malarious Parts of Africa-A Six Country Study. PLoS ONE, 3, e2132.

[20] Dondorp, A.M., Newton, P.N., Mayxay, M., Van Damme, W., Smithuis, F.M., Yeung, S., et al. (2004) Fake Antimalarials in Southeast Asia Are a Major Impediment to Malaria Control: Multinational Cross-Sectional Survey on the Prevalence of Fake Antimalarials. Tropical Medicine \& International Health, 9, 1241-1246. http://dx.doi.org/10.1111/j.1365-3156.2004.01342.x 